\title{
Diabetes and Periodontal Diseases: An Established Two-Way Relationship
}

\section{Carlos Arana Molina ${ }^{*}$, Luna Florencio Ojeda1, María Sevillano Jiménez ${ }^{1}$, Cristóbal Morales Portillo Isabel Serrano Olmedoㄹ, Tomás Martín Hernández ${ }^{1}$, Gerardo Gómez Moreno²}

\author{
${ }^{1}$ Department of Endocrinology and Nutrition, Virgen Macarena University Hospital, Seville, Spain \\ ${ }^{2}$ Department of Special Care in Dentistry, Pharmacological Research in Dentistry Group, \\ Faculty of Dentistry, University of Granada, Granada, Spain \\ Email: *carana@ugr.es
}

How to cite this paper: Molina, C.A., Ojeda, L.F., Jiménez, M.S., Portillo, C.M., Olmedo, I.S., Hernández, T.M. and Moreno, G.G. (2016) Diabetes and Periodontal Diseases: An Established Two-Way Relationship. Journal of Diabetes Mellitus, 6, 209229.

http://dx.doi.org/10.4236/jdm.2016.64024

Received: August 21, 2016

Accepted: September 10, 2016

Published: September 13, 2016

Copyright $\odot 2016$ by authors and Scientific Research Publishing Inc. This work is licensed under the Creative Commons Attribution International License (CC BY 4.0).

http://creativecommons.org/licenses/by/4.0/

\begin{abstract}
Background: Periodontal diseases (PD), including periodontitis, are chronic inflammatory pathologies caused by bacteria in the subgingival biofilm which affect the periodontal tissues. PD is now considered a localized, chronic, oral infection that activates the host immuno-inflammatory responses both locally and systemically, and also constitutes a source of bacteraemia. It is a known fact that periodontal diseases exercise an important influence on the pathogenesis of numerous systemic diseases, including diabetes mellitus (DM). In the mid-nineties, sufficient scientific evidence emerged to confirm an association between DM and periodontitis, which then began to be regarded as the sixth complication of DM. Current scientific evidence points to a two-way relationship between DM and periodontal disease, whereby DM is associated with an increase in the incidence and progression of periodontitis, while periodontal infection is associated with worsening glycemic control in diabetic patients. This two-way relationship points to a need to promote oral health in DM patients, and to implement a joint management protocol between endocrinologist and dentist that aims to create adequate conditions for early diagnosis and the effective treatment of both diseases.
\end{abstract}

\section{Keywords}

Diabetes Mellitus, Periodontitis, Periodontal Medicine, Two-Way Relationship

\section{Introduction}

Diabetes mellitus (DM) covers a group of metabolic diseases characterized by hyperglycaemia caused by defects in insulin secretion, insulin action, or both. The latest research by the International Diabetes Federation (IDF) states that $8.8 \%$ of adults (415 
million people) have DM and the number is expected to rise to some 642 million (one adult in ten) by the year 2040 [1]. So DM is a major healthcare concern because of its high prevalence and the enormous social and healthcare costs it incurs.

Another important aspect of this disease is the high morbidity and mortality it produces. Chronic hyperglycaemia, the main characteristic of badly managed DM, is associated with a wide range of acute and chronic complications that can affect all the body's organs and systems, including the gingival and periodontal tissues. Although periodontal diseases have not been "officially" recognized as a complication of DM, the scientific evidence available indicates that poor metabolic control may increase the risk of gingivitis and periodontitis [2]; these periodontal pathologies have also been associated with diverse systemic diseases closely related to DM, such as cardiovascular diseases, obesity and metabolic syndrome [3] [4].

This article reviews and updates current understanding of the complex relationship between DM and inflammatory periodontal diseases, focusing on the following aspects: the role of $\mathrm{DM}$ as a risk factor for periodontal diseases; the effect of periodontal infections on diabetic complications and the incidence DM; the mechanisms linking these entities; the effect of periodontal therapy on glycemic control in patients with DM; the implications of this association for health-care professionals.

\section{Periodontal Diseases}

The periodontium is the functional system of tissues that surround and support the tooth, and comprises root cementum, periodontal ligament, the bone lining the tooth socket (alveolar bone) and the part of the gingiva facing the tooth (dentogingival junction). Collectively, they function as a unit to keep the tooth in position, in spite of varying responses during mastication (Figure 1).

Periodontal diseases are chronic, microbially induced, inflammatory disorders that affect the structures that support the teeth, and include gingivitis and periodontitis [5]. Gingivitis is a localized, reversible inflammation of the gums. Dental plaque, which builds up on the tooth surfaces, is a sticky "biofilm" containing colonies of bacteria. Most of the 600 species of bacteria that may be found in the mouth are likely to be

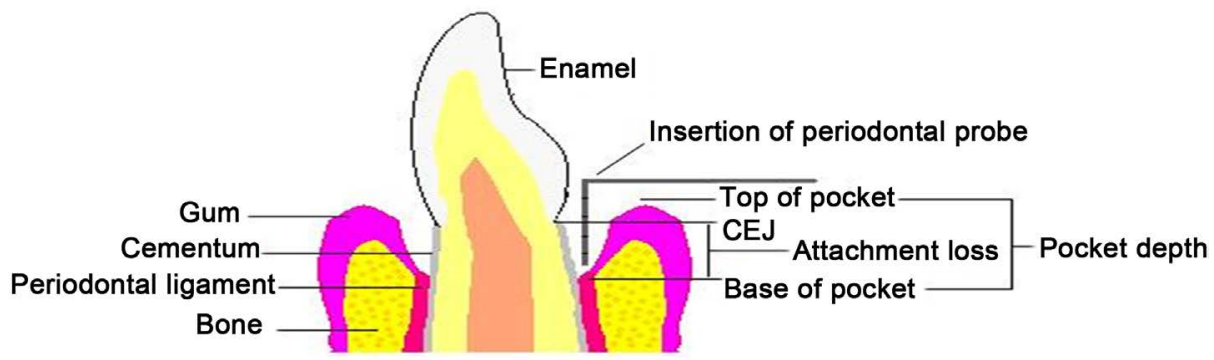

Figure 1. Illustration of the tissues that make up the periodontium, showing each clinical parameter and its measurement. In healthy periodontium, the base of the pocket is coincident with the cemento-enamel junction (CEJ, the boundary between enamel crown and the root) and there is no attachment loss. In periodontitis, the base of the pocket migrates apically, thereby creating a pocket. Adapted from Preshaw P.M., et al. (2012) Diabetologia, 55, 21-31. 
harmless, but some are known to be involved in oral diseases. Adequate oral hygiene, which includes brushing and flossing, aims to remove plaque, and is the principal treatment for gingivitis. This localized inflammation may or may not lead on to the more serious periodontitis, in which inflammation extends to the connective tissue and the bone supporting the tooth, resulting in tissue destruction, the consequent formation of periodontal pockets, and bone resorption. The final outcome is loss of clinical insertion and loss of the teeth [5]-[7].

Evaluating the prevalence of periodontal disease is complicated. Estimates largely depend on the diagnostic criteria adopted in each study. Some authors have suggested that $50 \%$ of all age groups in the US population have reversible gingival inflammation, with a prevalence of periodontitis of $14 \%$, although this might be even higher [7].

Studies of periodontal diseases include measures of gingivitis, according to Löe and Silness gingival index (with values from 0 to 3 , where 2 or 3 indicates bleeding) [8] and of periodontitis (assessed by a manual periodontal probe). "Probing pocket depth" is the distance between the gingival margin and the base of a pocket. "Attachment loss" is the distance between the cemento-enamel junction of the tooth and the base of a pocket. Bone loss (assessed by radiography), tooth loss, and both the severity (at any one site) and extent (number of teeth involved) may be included in the final measure of periodontitis. In the literature, the terms slight (or mild), moderate, and severe (or advanced) are used to classify periodontitis (Figure 2). Once the periodontium is affected, it is necessary to disrupt the biofilm mechanically (debridement, referred to as scaling), and allow healing; adjunctive antibiotic therapy may be used in some cases. Periodontium affectation is not something that can be treated by self-care, and so professional treatment is always necessary [6] [7].

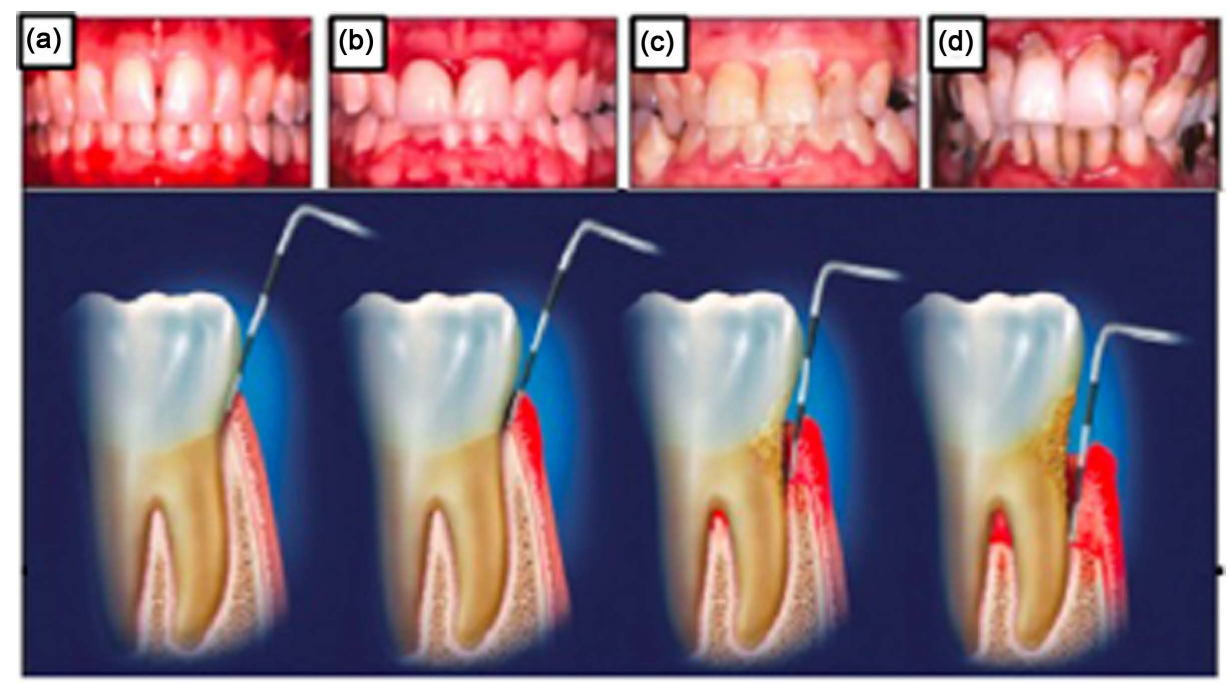

Figure 2. Anatomical illustration of the evolution of periodontal diseases from a state or periodontal health to severe chronic periodontitis. (a): Healthy periodontium; (b): Mild periodontitis; (c) Moderate periodontitis; (d): Severe/advanced chronic periodontitis. Supplied by: Report of the Independent Panel of Experts of The Scottsdale Project. Casey Hein, Charles Cobb, Anthony Iacopino, et al. Grand Rounds (2007). 
Current understanding is that periodontal diseases mainly begin with an inflammatory response to Gram-positive bacteria, manifested as gingivitis (red and swollen gums).

In susceptible individuals, the effects spread into the periodontium, down into a pocket between the gum and the tooth, where a change to Gram-negative bacteria takes place, and greater inflammatory response leading to breakdown of the connective tissue and bone. When this goes unchecked, there will be further changes in microflora, with further inflammation, and further destruction [7]. Although periodontal diseases have traditionally been considered a chronic condition localized in the oral cavity, with negative affects limited to the periodont, it is now known that they can activate host immune and inflammatory responses both locally and systemically, with systemic inflammatory effects detectable through increased serum levels of inflammatory markers such as C-reactive protein (CRP) and interleukin-6 (IL-6) [9]. So it is known that periodontal diseases play a relevant role in the pathogenesis of diverse systemic diseases, and may increase the risk of their presentation, a situation that has lead to the development of what is known as "Periodontal Medicine" [10].

\section{Dm and Periodontal Diseases: A Two-Way Relationship}

The biological relationship between DM and periodontal diseases has been well documented since the 1960s (although it was first described at a much earlier date) starting with the work by Belting et al. [11]. In the mid-nineties, after 30 years of exhaustive research and some 90 published epidemiological studies, the association between DM and periodontitis was established, and periodontitis has became known as the sixth complication of diabetes [12]. It was shown that DM was a risk factor for the appearance of periodontal diseases, and later an inverse relationship was proposed that periodontitis could be a risk factor for glycemic decompensation, as well as being associated with an increased risk of DM.

Numerous studies support this relationship. Shlossman et al. determined the periodontal state of 2878 subjects in a Pima Indian population (where a high proportion of type 2 diabetes mellitus is found), finding a higher prevalence of periodontitis among diabetic subjects, significantly higher than among non-diabetic subjects (OR 2.6; 95\% CI 1.0 - 6.6), age being an independent factor [13]. On the basis of this first study by Shlossman et al., Emrich et al. [14], Nelson et al. [15] and Taylor et al. [16] have obtained similar results in the same population. Data supplied by the National Health and Nutrition Examination Study (NHANES) III in the USA, in which 4343 patients aged between 45 and 90 years participated, concluded that individuals with poorly controlled DM (defined as glycosylated hemoglobin > 9\%) had a significantly higher prevalence of severe periodontitis than those without DM (OR 2.90; 95\% CI 1.40 - 6.03), after making adjustments for age, education, smoking status, and calculus. It was also observed that the prevalence of DM in patients with periodontitis was almost double that of patients without periodontitis [17]. Taylor and Borgnakke examined 17 cross-sectional studies made since 2000, and considered that these rein- 
forced the impression gained from a previous analysis of 48 observational studies dated 1960-2000, that DM adversely affects periodontal health [18]. Research carried out in the last few years has established a relation between the severity of periodontitis and type 2 DM complications [19] [20].

These findings have lead to extensive and wide-ranging research initiatives that have attempted to explain the association between DM and periodontal diseases. The present article details the evidence available to date regarding each component of this two-way relationship: firstly, DM as a risk factor for the appearance and progression of periodontal diseases; secondly, periodontal infections as an aggravating factor in poor glycemic control; and lastly, the pathogenic mechanisms that connect these two entities.

\subsection{DM as a Risk Factor of Periodontitis}

According to the available scientific evidence, DM is currently considered an established and highly relevant risk factor for the development of periodontitis, and contributes to its increasing prevalence, severity and progression [2] [21] [22].

Thorstensson and Hugoson performed a study of the prevalence of periodontal disease in individuals aged between 40 and 70 years in Sweden, comparing 83 insulindependent diabetic patients with 99 non-diabetic subjects; clinical and radiological examinations were performed to evaluate the patients' periodontal state [23]. The results showed that among younger (40 - 49 years) diabetic patients, a higher number of periodontal pockets $>6 \mathrm{~mm}$ and greater alveolar bone loss were seen than in healthy subjects of the same age. In diabetic patients aged 50 - 59 years and 60 - 69 years, no significant differences were found in comparison with the non-diabetic group. So age was considered an important risk factor for periodontal destruction, suggesting that early onset of DM is a more important risk factor for periodontium loss than the duration of the disease. Mealey affirmed that after making adjustments for confounding factors such as age or sex, DM would appear to increase the probability of presenting periodontitis by three times [24].

A systematic review by Chávarry et al. published in 2009 set out to determine whether DM is associated with severe periodontitis (after adjusting for confounding factors), and whether DM influences responses to periodontal therapy [25]. Of the 49 transversal studies that met review's inclusion criteria, 27 documented more widespread and more severe periodontitis in diabetic patients than those without DM. Meta-analysis showed a statistically significant difference in clinical insertion of $1 \mathrm{~mm}$ (95\% CI $0.15-1.84 \mathrm{~mm}$ ) between diabetic and non-diabetic subjects. This difference was registered mainly among type $2 \mathrm{DM}$ patients, while the insertion differences between type $1 \mathrm{DM}$ patients and non-diabetic subjects (control) were not statistically significant. The researchers attributed this finding to the young age of the patients with type $1 \mathrm{DM}$ taking part in most of the studies, and the reduced possibility of their presenting periodontitis of greater severity.

However, one case-control study reported periodontal findings in children aged 6 - 
18 years with type $1 \mathrm{DM}$ and control subjects without DM, obtaining approximately four times higher prevalence of teeth with clinical insertion loss in diabetic children (5.8 compared with 1.5 affected teeth per subject, $\mathrm{p}<0.01$ ) a statistically significant difference after adjustment for age, sex, gingival bleeding (a sign of gingival inflammation) and frequency of visits to the dentist reported by the subjects [26]. In an expanded study by the same research group, that included 350 children with DM (95\% with type $1 \mathrm{DM}$ ) and 350 non-diabetic control subjects (also children), the effect of DM on periodontal destruction remained statistically significant in both a subgroup of younger (6 - 11 years) and older children (12 - 18 years) [27]. The mean glycosylated hemoglobin level (HbA1c) 2 years prior to dental examination was associated with the quantity of periodontal destruction after making adjustments for age (although adjustments for DM duration and body mass were not made) [28].

Of eight longitudinal studies included in the literature review by Chávarry et al. [25], four [29]-[32] compared the rate of progress of periodontal disease in individuals with and without DM, of which three reported the accelerated progression of periodontitis in DM patients. A prospective study not included in the former, of periodontitis progression and glycemic control conducted in a population of Gullah Afro-Americans with type $2 \mathrm{DM}$, showed accelerated periodontitis progression in patients with poor metabolic control $(\mathrm{HbAlc} \geq 7 \%)$ in comparison with patients with good metabolic control (HbAlc $<7 \%)$ [33].

As for the question of whether or not DM exerts an influence on the treatment of periodontal disease, of four longitudinal studies evaluating the effects of DM on responses to periodontal therapies [34]-[37], three did not identify a lower curative response by periodontal tissues in patients with $\mathrm{DM}$, in comparison with the response observed in non-diabetic patients. So, the outcomes of periodontal therapy in diabetic subjects, registered in terms of clinical variables (reduction of periodontal pocket depth and bleeding, stabilized insertion depth) showed overall similarity across diabetic and non-diabetic subjects.

Lastly, it is important to stress that the available epidemiological evidence points to a positive association between obesity, metabolic syndrome (two entities closely related to type $2 \mathrm{DM}$ ) and periodontitis [4] [38]-[43]. Although the present work's objective was not to carry out a detailed review of these studies, the findings are concurrent with the concept that type $2 \mathrm{DM}$ is a risk factor for periodontal disease.

\subsection{Impact of Periodontitis on Diabetic Complications and DM Incidence}

Not only is DM a risk factor for periodontal disease but periodontal disease can also have a negative effect on glycemic and metabolic control in diabetic patients. The first evidence in support of this hypothesis originated in research carried out among subjects belonging to the indigenous population on the river Gila (New Mexico). It was found that severe periodontitis at the outset of the study was associated with poor glycemic control ( $\mathrm{HbAlc}>9.0 \%$ ) during the follow-up period (a minimum of 2 years), 
which suggests that severe periodontitis is a risk factor that compromises DM management [44]. Furthermore, diverse studies have reported that the prevalence and severity of non-oral complications of DM, including retinopathy, diabetic neuropathy, proteinuria and cardiovascular complications, were correlated with the severity of the periodontitis [45]-[48].

Other studies of the Indian community on the river Gila have investigated the effect of periodontitis on the development of renal disease and end stage renal disease (ESRD) in type $2 \mathrm{DM}$ patients [49]. The periodontal state of 529 individuals aged $>25$ years with type $2 \mathrm{DM}$, a glomerular filtration rate of $\geq 60 \mathrm{ml} / \mathrm{min}^{-1} / 1.73 \mathrm{~m}^{-2}$, without macroalbuminuria (defined as a urinary albumin / creatinine quotient of $\geq 300 \mathrm{mg} / \mathrm{g}$ ). A total of 93 subjects developed macroalbuminuria (during an average follow-up period of 14.9 years). After making adjustments for age, sex, DM duration, body mass index and smoking, the incidence of macroalbuminuria was 2.0, 2.1 and 2.6 times higher in subjects with moderate or severe periodontitis, or edentulous subjects respectively, in comparison with those with slight or no periodontitis $(\mathrm{p}<0.05)$. The incidence of end stage renal disease (ESRD) was 2.3, 3.5 and 4.9 times higher for subjects with moderate or severe periodontitis, or edentulous subjects, respectively $(\mathrm{p}<0.05)$. So moderate or severe periodontitis or edentulism predicted the development of overt nephropathy and end stage renal disease "dose-dependently" in patients with type 2 DM, individuals with type 2 DM mellitus and little or no pre-existing kidney disease [49].

The same authors also investigated the effect of periodontitis on death from cardiovascular disease and diabetic nephopathy. In a longitudinal study carried out among 628 Pima Indians, aged > 35 years, with type 2 DM (average follow-up of 11 years, during which time 204 patients died), mortality rates adjusted for age and sex (number of deaths per 1000 subjects per year) were 3.7 for subjects with no or slight periodontitis, 19.6 for those with moderate periodontitis, and 28.4 for those with severe periodontitis. Periodontitis was a predictive factor for death by ischemic heart disease $(\mathrm{p}=0.04)$ and diabetic nephropathy $(\mathrm{p}<0.01)$. After adjustment for possible confounding factors (age, sex, DM duration, HbA1c, macroalbuminuria, body mass index, cholesterol levels, hypertension, electrocardiographic anomalies and smoking), diabetic subjects with severe periodontitis were subject to 3.2 times greater risk (95\% CI 1.1 - 9.3) of cardio-renal mortality (combined ischemic heart disease and diabetic nephropathy) in comparison with the control group (no or slight periodontal disease, and moderate periodontal disease combined) [20]. According to researchers, inflammation associated with periodontal disease may play a central role in the pathogenesis of cardiovascular diseases (CVD). As with other chronic infections, chronic periodontal disease is associated with systemic changes in blood and blood-forming organs, which may result in activation of markers of inflammation and acute- phase proteins such as C-reactive protein. Studies of diabetes and CVD suggest that low-level, chronic inflammation is associated with endothelial dysfunction, a pathway potentially linking diabetes and periodontal disease to CVD.

Another important aspect of this type of research is to determine whether perio- 
dontal diseases play a relevant role in the incidence of DM. A prospective 7-year study of 5,848 subjects aged 30 - 59 years evaluated the effect of periodontitis on the incidence of DM (defined as fasting plasma glucose $>6.9 \mathrm{mmol} / \mathrm{l}$, equivalent to $>125 \mathrm{mg} / \mathrm{dl}$ ) [50]. In unadjusted analysis, moderate (pockets of 3.5-5.5 mm) and severe periodontitis (pockets $>5.5 \mathrm{~mm}$ ) were significantly associated with an increased incidence of DM, but statistical significance was lost after adjusting for sex, smoking, body mass index, triglycerides, hypertension, cholesterol and gamma-glutamyl transpeptidase.

The impact of periodontitis on changes in $\mathrm{HbAlc}$ was evaluated in a 5-year prospective study of 2973 non-diabetic subjects [51]. Subjects with more advanced periodontitis at the start of the study showed absolute increases in HbAlc approximately five times greater after the 5-year follow-up in comparison with those who presented no periodontitis at the start of the study (change in HbAlc $0.106 \pm 0.03 \%$ vs. $0.023 \pm 0.02 \%)$. This was the first study to report that periodontitis predicts increases in $\mathrm{HbAlc}$ among individuals without DM. Authors argued that periodontal pathogens can stimulate production of inflammatory cytokines such as tumor necrosis factor alpha (TNFa), inducing a state of insulin resistance and systemic inflammation that has also emerged as a novel predictor of incident diabetes. It remains to see whether these subclinical changes translate into an increased incidence of DM in the long term.

More recently, the same author has evaluated the relationship between periodontal microbiota and early DM risk in a cross-sectional study that included 300 DM-free adults aged 20 - 55 years. Although the prevalence ratio for pre-DM among participants with moderate/severe vs. no/mild periodontitis was 1.47 (95\% CI $0.78-2.74$ ), without statistical significance $(\mathrm{p}=0.23)$, higher colonization levels of specific periodontal microbiota were associated with higher pre-DM prevalence among DM-free adults [52].

In conclusion, current scientific evidence suggests that there is an increased risk of developing DM in individuals with severe periodontitis, in comparison with subjects with good periodontal health or only slight periodontitis. Furthermore, studies show that the incidences of macroalbuminuria and end-stage renal disease are increased two-fold and threefold, respectively, in diabetic individuals who also have severe periodontitis. Furthermore, people with DM and severe periodontitis show three times the risk of cardio-renal mortality compared with those without severe periodontitis.

\section{Mechanisms Linking DM and Periodontal Infections}

As mentioned previously, periodontal diseases, and among them periodontitis, are pathologies of complex and multifactorial etiology, but share a common characteristic, which is the presence of chronic inflammation in the periodontal tissues with the formation of periodontal pockets (Figure 1), associated with bacteria organized in subgingival biofilms. Chronic inflammation provokes the activation and excessive secretion of inflammatory mediators that are responsible for connective tissue and alveolar bone destruction. Among these are interleukins $1 \beta$ (IL-1 $\beta$ ) and 6 (IL-6), 
prostaglandin E2 $\left(\mathrm{PGE}_{2}\right)$, tumor necrosis factor alpha (TNF $\left.\alpha\right)$, Receptor activator of nuclear factor kappa-B ligand (RANKL), matrix metalloproteinases (MMP), cytokines, regulatory T cells (IL-12, IL-18) and chemokines [53].

As well as characteristic of periodontitis, inflammation is also characteristic of DM, constituting the main nexus between the two entities. In this way, DM is associated with high levels of systemic markers of inflammation [54], which contribute to micro and macrovascular complications. It has been shown that chronic hyperglycaemia activates different pathways that result in increased inflammation, oxidative stress and apoptosis [55]. In these processes, high blood levels of IL-6 and TNF $\alpha$ would appear to be key elements, with the associated increase in acute-phase proteins such as C-reactive protein. Given the importance of inflammation in both pathologies, the most widely accepted hypothesis postulates that DM could boost the inflammatory response of periodontal tissues (Figure 3). Various studies have supported this hypothesis. For example, $\mathrm{PGE}_{2}$ and IL-1 $\beta$ values in gingival crevicular fluid (GCF) are higher in patients with type $1 \mathrm{DM}$ and gingivitis or periodontitis in comparison with nondiabetic subjects with the same levels of periodontal disease. In a study of type 2 DM patients, those presenting HbAlc $>8 \%$ presented significantly higher IL- $1 \beta$ values in GCF than patients with $\mathrm{HbAlc}<8 \%, \mathrm{HbAlc}$ and glucose values being independent

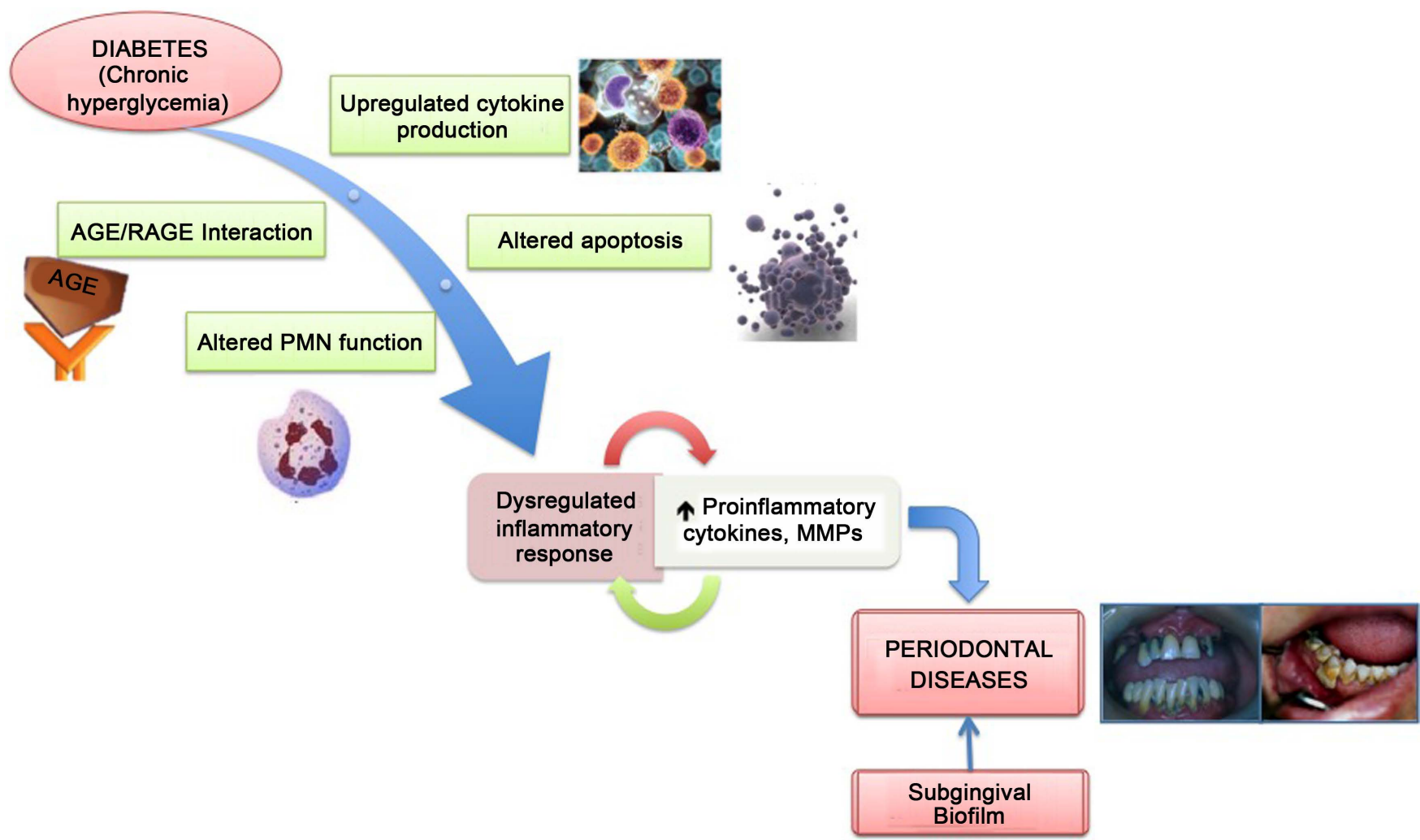

Figure 3. Illustration of the mechanisms of interaction between diabetes and periodontal diseases. The most widely accepted hypothesis is that diabetes increases inflammatory responses of the peridontal tissues. Exacerbated and dysregulated inflammatory responses are the key to the proposed two-way relationship between diabetes and periodontal diseases. AGE: advanced glycosylation end-products; MMP: extracellular matrix metalloproteinases; PMN: polymorphonuclear leukocytes; RAGE: receptor of advanced glycosylation end-products. 
predictors of high IL-1 $\beta$ values in GCF [56] [57]. At the same time, it is well known that diabetic patients present defects in polymorphonuclear leukocyte (PMNL) activity, including chemotaxis, phagocytosis and bactericidal function disorders. Shetty et al. studied PMN functions in 15 diabetic patients with chronic generalized periodontitis, and found that chemotaxis, superoxide production, phagocytosis and killing of Porphyromonas gingivalis by diabetic PMNs were impaired significantly in comparison with healthy control subjects [58]. Similarly, other studies have shown that diabetic patients with severe periodontitis present reduced chemotaxis in comparison with diabetic subjects with only slight periodontitis, as well as defective apoptosis, which can lead to an increase in PMN retention in the periodontal tissues, which will be accompanied by greater tissue destruction due to continuous MMP and reactive oxygen species (ROS) secretion [56] [57].

A second element for consideration in this two-way relationship is the role of Advanced Glycation End-products (AGEs). AGEs are composites derived from the nonenzymatic, irreversible glycosylation of proteins and lipids that accumulate in plasma, on the walls of blood vessels and tissues in diabetic patients, which are the main element responsible for the development of the micro and macrovascular complications characteristic of DM [59]. It is known that gingival macrophages present receptors with high affinity for AGEs (RAGE), so that they accumulate in the periodontal tissues of diabetics. A study by Schmidt et al. [60] showed that the gingival tissue of adult patients diagnosed with DM who were subjected to surgical periodontal treatment, presented higher quantities of AGEs than that of non-diabetic subjects. This finding is important as the accumulation of AGEs in the periodontal tissues of diabetic patients favors frequent pro-inflammatory episodes. When AGE binds to its receptor, this produces an overproduction of inflammatory mediators such as IL-1 $\beta$, TNF- $\alpha$ and IL-6 [56] [57] [61]. The formation of these molecules provokes ROS production, which increases oxidative stress, and the consequent cellular changes that take place contribute to the vascular damage involved in many DM complications [62]-[66]. AGEs also increase the respiratory burst of PMNs, which has the potential to increase tissue damage localized in the periodontium. In addition, AGEs have a harmful effect on bone metabolism, producing an alteration to the bone formation and repair mechanisms, together with reduced production of extracellular matrix. Apoptosis may play a role in the increased susceptibility to periodontal diseases among diabetics, and the death of matrix-producing cells could limit the possibility of repair in inflamed tissues; it is known that AGEs have harmful effects on extracellular matrix formation, in relation to apoptosis of the cells most involved in its formation such as fibroblasts [57].

A third element for consideration is the changes that DM may cause in the composition of subgingival microbiota. Compared with the large number of studies that have investigated the role of inflammatory mechanisms in the relation between DM and periodontal diseases, relatively few have focused on the changes triggered by changes to oral microbiota. The few that exist indicate that in general there are more similarities than differences between diabetic and non-diabetic subjects. Nevertheless, some significant 
differences have been detected, such as the greater prevalence of Porphyromonas gingivalis [67] and Prevotella intermedia [67] [68] in diabetic subjects. These studies indicate that there are probably subtle differences between diabetics and non-diabetics, although the clinical relevance of these differences is not clear. The origins of these differences could lie in the previously observed effects on periodontal tissues that could favor the growth of more pathogenic species. Figure 3 illustrates schematically the mechanisms of interaction between DM and periodontitis.

\section{Does Periodontal Treatment Affect Metabolic Control in DM?}

Researchers have attempted to demonstrate the effect of periodontal treatment on the metabolic control in DM, and there would appear to be good evidence in support of this hypothesis as the treatment of periodontal diseases has been seen to improve not only the clinical and immunological parameters of periodontitis but also long-term glycemic control in DM [69]-[71]. Kiran et al. performed a randomized controlled clinical study of 44 type $2 \mathrm{DM}$ patients with different degrees of periodontal disease. Subjects were randomly assigned into two groups: a treatment group (that underwent full-mouth scaling and root planning, performed under local anesthesia) and a non-treatment group (control group, who only received oral hygiene instructions). The authors obtained a $50 \%$ reduction in the prevalence of gingival bleeding in the treatment group after three months. In addition, $\mathrm{HbA1c}$ levels in the treatment group decreased significantly (from $7.31 \%$ to $6.51 \%$, approximately $10.94 \%$ of the baseline level) whereas the control group showed $4.42 \%$ increases in levels of $\mathrm{HbAlc}$, although these were not statistically or clinically significant [69].

Faria-Almeida et al. [37] also demonstrated that the treatment of periodontal diseases significantly improves metabolic control of DM. These authors performed a controlled 6-month clinical study of 20 patients divided into two groups (type 2 diabetes and non-diabetics), with moderate generalized chronic periodontitis. Conventional periodontal scaling and root planing were performed, and the response to this treatment was compared between the groups at 3 and 6 months. An improvement in all clinical variables was observed, with no statistically significant differences between the groups, with the exception of probing depth. The improvement observed in blood HbA1c levels confirmed a positive metabolic response to periodontal treatment, with a lower value for this variable at 3 and 6 months after periodontal treatment.

In 2008, Singh et al. made a study of 45 patients with type $2 \mathrm{DM}$ and generalized periodontitis [71]. Patients were divided into three groups of 15: Group A received treatment with full mouth scaling and root planing only; Group B received treatment with full mouth scaling and root planing followed by systemic doxycycline (100 mg daily for 14 days); and Group $C$ received no treatment (control group). They found that Groups A and B showed a mean difference of $0.60 \%$ and $0.78 \%$ in HbAlc values, respectively, over the period of 3 months vs. group $C$ without treatment $(p<0.05)$.

In spite of the promising results of these studies, it should be noted that few randomized clinical studies have been conducted, and the results are variable and at times 
contradictory. They vary in terms of both the type of treatment and the type of DM, although most have studied patients with type $2 \mathrm{DM}$. Generally, the results indicate that periodontal treatment, including root scaling and planning improves glycemic control in type 2 DM [69] [72] [73], although some do not report any improvement [74]. Fewer studies have been conducted among type $1 \mathrm{DM}$ patients and the results are contradictory [75] [76].

Systematic literature reviews with meta-analysis have also established that an improvement in DM metabolic control occurs after periodontal treatment. The first of these analyzed 10 studies involving periodontal intervention. A total of 456 type 1 and type 2 diabetic patients were included in this analysis, with periodontal treatment as predictor and the change in $\mathrm{HbAlc}$ level as outcome [77]. The results showed a mean reduction in HbAlc levels of $0.38 \%$ over all the studies analyzed, and $0.66 \%$ when analysis was limited to type $2 \mathrm{DM}$ patients, and $0.71 \%$ if antibiotics were administered as a part of treatment; however, none of these findings were statistically significant.

In 2010, Teeuw et al. [78] carried out a systematic review with meta-analysis of five controlled studies with 3-month follow-ups, in which patients in the control group did not receive periodontal treatment; meta-analysis showed an improvement in $\mathrm{HbAlc}$ values in type $2 \mathrm{DM}$ patients who received periodontal treatment $(-0.40 \%$, 95\% CI -0.77 to $-0.04 \%, p=0.03$ ), although the authors point out that the findings should be treated with caution due to the heterogeneity of the studies analyzed.

In a transversal study by Spangler et al. [79] of 5103 diabetic patients aged between 40 and 70 years, the subjects who received at least one periodontal surgery session (an intensive treatment type not routinely indicated for all patients with periodontitis) showed HbA1c levels $0.25 \%$ lower than those who did not receive treatment.

In 2012, Gurav made a systematic review to determine the effect of periodontal treatment on metabolic control in type $2 \mathrm{DM}$ patients [80]. It was concluded that periodontal therapy might be an adjuvant procedure in anti-diabetic treatment for these patients, although glycemic control did not improve in isolation. He also stressed the need for randomized controlled multi-centre clinical studies to verify the hypothesis.

More recently, a systematic review with meta-analysis by the 2015 Cochrane Collaboration included 35 studies, with a total of 2,565 participants with type 1 or type $2 \mathrm{DM}$, diagnosed with periodontitis [81]; they concluded that there was low quality evidence that the treatment of periodontal disease improves glycemic control in DM patients, with a mean $\mathrm{HbAlc}$ reduction of $0.29 \%$ after $3-4$ months, but without sufficient evidence to demonstrate that this effect will continue after the fourth month. They point out that larger, well-conducted and clearly reported studies are needed in order to understand the potential of periodontal treatment for improving glycemic control among DM patients.

Taken together, the meta-analyses and other available evidence indicate that $\mathrm{HbAlc}$ reductions of around $0.4 \%$ can be expected after effective periodontal therapy, although there are few controlled, randomized, multi-center studies available and some of them lack adequate statistical power. The mechanisms that produce this effect remain unclear, but it is probably due to a reduction in systemic inflammation (for example, reduction of 
serum levels of mediators such as TNF- $\alpha$ and IL-6) after treatment and resolution of periodontal inflammation. These findings are important because reductions in $\mathrm{HbAlc}$ are associated with a lower risk of diabetic complications. Epidemiological analysis of data obtained in The UK Prospective Diabetes Study (UKPDS) show a continuous relationship between the risks of microvascular complications and glycaemia, so that for every $1 \%$ of $\mathrm{HbA} 1 \mathrm{c}$ reduction occasions a $37 \%$ reduction in the risk of complications, a $14 \%$ reduction in the risk of myocardial infarction, and a $21 \%$ reduction in any DM-related endpoint [82].

In light of the above, it is now considered that there is sufficient evidence to justify further research into the contribution of periodontal treatment to metabolic control in diabetic patients. As several authors have pointed out, the prevention and management of periodontal disease must be considered an integral part of DM management [83].

\section{Implications for Health-Care Professionals}

Clearly, oral and periodontal healthcare must form an integral part of DM management [56]. In this context, improved understanding of the relationship between DM and periodontal disease must be disseminated not only among healthcare professionals but also among DM patients. Many DM patients remain unaware of the complications involved in the disease they suffer (including those of the oral cavity) and they often receive scant information about these from healthcare professionals. It is necessary to train professionals and inform patients about the benefits of oral healthcare in relation to DM. This has clear clinical implications as stated by Watanabe [84], pointing to the need for direct collaboration between the endocrinologist and the dentist in the treatment of diabetics with periodontal disease.

In fact, oral healthcare professionals have a valuable opportunity to identify undiagnosed DM or pre-diabetes among dental patients, and refer these patients to the GP or endocrinologist [85]-[87].

On this basis, the International Diabetes Federation has established a series of recommendations for periodontal care of diabetic patients [7]:

- As part of their initial assessment, type 1 and type 2, and gestational DM patients should be advised to undergo an exhaustive dental and oral examination that includes a complete periodontal examination.

- Annual assessment should be made to determine that the patient id fulfilling the daily recommended oral healthcare regime and to ensure that he/she attends regular dental check-ups that focus of the symptoms relating to periodontal diseases (bleeding on tooth brushing, reddened or inflamed gums, gingival retraction, dental movement).

- If some degree of periodontal disease is present, then regular 6-monthly check-ups by the dentist are advisable.

- If patients fail to perform adequate daily oral care, they should be reminded that this is an integral part of DM management, and of the importance of regular dental check-ups. 


\section{Conclusions}

As the literature reviewed in this paper makes clear, the association between DM and periodontal diseases is an established fact; it is clear that glycemic control improves periodontal conditions, while the management of periodontal infection improves the metabolic status of diabetic patients. In this context, the clinical implications of this two-relationship should be a focus for further research. Furthermore, the possibility that both diseases have several pathogenic features in common should make it possible to guarantee the early diagnosis of both.

In light of the high prevalence of both diseases and the severity of the possible repercussions for patients' health, the endocrinologist should play a key role in referring patients to the dentist on a regular basis in order to monitor risk factors such as the ongoing presence of bacterial plaque in periodontal pockets. Healthcare pro- fessionals should also remember that disordered glucose metabolism can affect the development and severity of periodontal diseases.

Further clinical, microbiological, biochemical and epidemiological studies are needed with large patient samples, including both type 1 and type 2 DM patients, well-designed randomized, controlled trials that compare different treatment modalities with the ultimate objective of establishing a clear strategy for multidisciplinary treatment of diabetic patients with periodontal disease.

\section{Conflict of Interest}

None declared.

\section{References}

[1] International Diabetes Federation (2015) IDF Diabetes. 7th Edition, International Diabetes Federation, Brussels, Belgium. http://www.diabetesatlas.org

[2] Salvi, G.E., Carollo-Bittel, B. and Lang, N.P. (2008) Effects of Diabetes Mellitus on Periodontal and Peri-Implant Conditions: Update on Associations and Risks. Journal of Clinical Periodontology, 35, 398-409. http://dx.doi.org/10.1111/j.1600-051X.2008.01282.x

[3] Bahekar, A.A., Singh, S., Saha, S., Molnar, J. and Arora, R. (2007) The Prevalence and Incidence of Coronary Heart Disease Is Significantly Increased in Periodontitis: A MetaAnalysis. American Heart Journal, 154, 830-837. http://dx.doi.org/10.1016/j.ahj.2007.06.037

[4] Li, Y., Lu, Z., Zhang, X., Yu, H., Kirkwood, K.L., Lopes-Virella, M.F., et al. (2015) Metabolic Syndrome Exacerbates Inflammation and Bone Loss in Periodontitis. Journal of Dental Research, 94, 362-370. http://dx.doi.org/10.1177/0022034514561658

[5] Pihlstrom, B.L., Michalowicz, B.S. and Johnson, N.W. (2005) Periodontal Diseases. The Lancet, 366, 1809-1820. http://dx.doi.org/10.1016/S0140-6736(05)67728-8

[6] Haffajee, A.D., Teles, R.P., Patel, M.R., Song, X., Veiga, N. and Socransky, S.S. (2009) Factors Affecting Human Supragingival Biofilm Composition. I. Plaque Mass. Journal of Periodontal Research, 44, 511-519. http://dx.doi.org/10.1111/j.1600-0765.2008.01154.x

[7] IDF Clinical Guidelines Task Force (2009) IDF Guideline on Oral Health for People with Diabetes. International Diabetes Federation, Brussels.

[8] Löe, H. (1967) The Gingival Index, the Plaque Index and the Retention Index Systems. 
Journal of Periodontology, 38, 610-616. http://dx.doi.org/10.1902/jop.1967.38.6_part2.610

[9] Moutsopoulos, N.M. and Madianos, P.N. (2006) Low-Grade Inflammation in Chronic Infectious Diseases: Paradigm of Periodontal Infections. Annals of the New York Academy of Sciences, 1088, 251-264. http://dx.doi.org/10.1196/annals.1366.032

[10] Gulati, M., Anand, V., Jain, N., Anand, B., Bahuguna, R., Govila, V., et al. (2013) Essentials of Periodontal Medicine in Preventive Medicine. International Journal of Preventive Medicine, 4, 988-994.

[11] Belting, C.M., Hiniker, J.J. and Dummett, C.O. (1964) Influence of Diabetes Mellitus on the Severity of Periodontal Disease. Journal of Periodontology, 8, 34-39. http://dx.doi.org/10.1902/jop.1964.35.6.476

[12] Löe, H. (1993) Periodontal Disease: The Sixth Complication of Diabetes Mellitus. Diabetes Care, 16, 329-334. http://dx.doi.org/10.2337/diacare.16.1.329

[13] Shlossman, M., Knowler, W.C., Pei, D.J. and Genco, R.J. (1990) Type 2 Diabetes Mellitus and Periodontal Disease. The Journal of the American Dental Association, 121, 532-536. http://dx.doi.org/10.14219/jada.archive.1990.0211

[14] Emrich, L.J., Shlossman, M. and Genco, R.J. (1991) Periodontal Disease in Non-InsulinDependent Diabetes Mellitus. Journal of Periodontology, 62, 123-131. http://dx.doi.org/10.1902/jop.1991.62.2.123

[15] Nelson, R.G., Shlossman, M., Budding, L.M., Pettitt, D.J., Saad, M.F., Genco, R.J., et al. (1990) Periodontal Disease and NIDDM in Pima Indians. Diabetes Care, 13, 836-840. http://dx.doi.org/10.2337/diacare.13.8.836

[16] Taylor, G.W., Burt, B.A., Becker, M.P., Genco, R.J. and Shlossman, M. (1998) Glycemic Control and Alveolar Bone Loss Progression in Type 2 Diabetes. Annals of Periodontology, 3, 30-39. http://dx.doi.org/10.1902/annals.1998.3.1.30

[17] Tsai, C., Hayes, C. and Taylor, G.W. (2002) Glycemic Control of Type 2 Diabetes and Severe Periodontal Disease in the US Adult Population. Community Dentistry and Oral Epidemiology, 30, 182-192. http://dx.doi.org/10.1034/j.1600-0528.2002.300304.x

[18] Taylor, G.W. and Borgnakke, W.S. (2008) Periodontal Disease: Associations with Diabetes, Glycemic Control and Complications. Oral Diseases, 14, 191-203. http://dx.doi.org/10.1111/j.1601-0825.2008.01442.x

[19] Mealey, B.L. and Oates, T.W. (2006) Diabetes Mellitus and Periodontal Diseases. Journal of Periodontology, 77, 1289-1303. http://dx.doi.org/10.1902/jop.2006.050459

[20] Saremi, A., Nelson, R.G., Tulloch-Reid, M., Hanson, R.L., Sievers, M.L., Taylor, G.W., et al. (2005) Periodontal Disease and Mortality in Type 2 Diabetes. Diabetes Care, 28, 27-32. http://dx.doi.org/10.2337/diacare.28.1.27

[21] Khader, Y.S., Dauod, A.S., El-Qaderi, S.S., Alkafajei, A. and Batayha, W.Q. (2006) Periodontal Status of Diabetics Compared with Nondiabetics: A Meta-Analysis. Journal of Diabetes and Its Complications, 20, 59-68. http://dx.doi.org/10.1016/j.jdiacomp.2005.05.006

[22] Botero, J.E., Yepes, F.L., Roldán, N., Castrillón, C.A., Hincapie, J.P., Ochoa, S.P., et al. (2012) Tooth and Periodontal Clinical Attachment Loss Are Associated with Hyperglycemia in Patients with Diabetes. Journal of Periodontology, 83, 1245-1250. http://dx.doi.org/10.1902/jop.2012.110681

[23] Thorstensson, H. and Hugoson, A. (1993) Periodontal Disease Experience in Adult Long Duration Insulin-Dependent Diabetics. Journal of Clinical Periodontology, 20, 352-358. http://dx.doi.org/10.1111/j.1600-051X.1993.tb00372.x

[24] Mealey, B.L. (1998) How Does Diabetes Alter Treatment in the Dental Office? Journal 
Indiana Dental Association, 77, 11-15.

[25] Chávarry, N.G., Vettore, M.V., Sansone, C. and Sheiham, A. (2009) The Relationship between Diabetes Mellitus and Destructive Periodontal Disease: A Meta-Analysis. Oral Health \& Preventive Dentistry, 7, 107-127.

[26] Lalla, E., Cheng, B., Lal, S., Tucker, S., Greenberg, E., Goland, R., et al. (2006) Periodontal Changes in Children and Adolescents with Diabetes: A Case-Control Study. Diabetes Care, 29, 295-299. http://dx.doi.org/10.2337/diacare.29.02.06.dc05-1355

[27] Lalla, E., Cheng, B., Lal, S., Kaplan, S., Softness, B., Greenberg, E., et al. (2007) Diabetes Mellitus Promotes Periodontal Destruction in Children. Journal of Clinical Periodontology, 34, 294-298. http://dx.doi.org/10.1111/j.1600-051X.2007.01054.x

[28] Lalla, E., Cheng, B., Lal, S., Kaplan, S., Softness, B., Greenberg, E., et al. (2007) DiabetesRelated Parameters and Periodontal Conditions in Children. Journal of Periodontal Research, 42, 345-349. http://dx.doi.org/10.1111/j.1600-0765.2006.00955.x

[29] Novaes Jr., A.B., Gutierrez, F.G. and Novaes, A.B. (1996) Periodontal Disease Progression in Type II Non-Insulin-Dependent Diabetes Mellitus Patients (NIDDM). Part I-Probing Pocket Depth and Clinical Attachment. Brazilian Dental Journal, 7, 65-73.

[30] Firatli, E. (1997) The Relationship between Clinical Periodontal Status and Insulin-Dependent Diabetes Mellitus. Results after 5 Years. Journal of Periodontology, 68, 136-140. http://dx.doi.org/10.1902/jop.1997.68.2.136

[31] Sbordone, L., Ramaglia, L., Barone, A., Ciaglia, R.N. and Iacono, V.J. (1998) Periodontal Status and Subgingival Microbiota of Insulin-Dependent Juvenile Diabetics: A 3-Year Longitudinal Study. Journal of Periodontology, 69, 120-128. http://dx.doi.org/10.1902/jop.1998.69.2.120

[32] Taylor, G.W., Burt, B.A., Becker, M.P., Genco, R.J., Shlossman, M., Knowler W.C., et al. (1998) Non-Insulin Dependent Diabetes Mellitus and Alveolar Bone Loss Progression over 2 Years. Journal of Periodontology, 69, 76-83. http://dx.doi.org/10.1902/jop.1998.69.1.76

[33] Bandyopadhyay, D., Marlow, N.M., Fernandes, J.K. and Leite, R.S. (2010) Periodontal Disease Progression and Glycaemic Control among Gullah African Americans with Type-2 Diabetes. Journal of Clinical Periodontology, 37, 501-509. http://dx.doi.org/10.1111/j.1600-051X.2010.01564.x

[34] Westfelt, E., Rylander, H., Blohmé, G., Jonasson, P. and Lindhe, J. (1996) The Effect of Periodontal Therapy in Diabetics. Results after 5 Years. Journal of Clinical Periodontology, 23, 92-100. http://dx.doi.org/10.1111/j.1600-051X.1996.tb00540.x

[35] Tervonen, T. and Karjalainen, K. (1997) Periodontal Disease Related to Diabetic Status. A Pilot Study of the Response to Periodontal Therapy in Type 1 Diabetes. Journal of Clinical Periodontology, 24, 505-510. http://dx.doi.org/10.1111/j.1600-051X.1997.tb00219.x

[36] Christgau, M., Palitzsch, K.D., Schmalz, G., Kreiner, U. and Frenzel, S. (1998) Healing Response to Non-Surgical Periodontal Therapy in Patients with Diabetes Mellitus: Clinical, Microbiological, and Immunologic Results. Journal of Clinical Periodontology, 25, 112-124. http://dx.doi.org/10.1111/j.1600-051X.1998.tb02417.x

[37] Faria-Almeida, R., Navarro, A. and Bascones, A. (2006) Clinical and Metabolic Changes after Conventional Treatment of Type 2 Diabetic Patients with Chronic Periodontitis. Journal of Periodontology, 77, 591-598. http://dx.doi.org/10.1902/jop.2006.050084

[38] Shimazaki, Y., Egami, Y., Matsubara, T., Koike, G., Akifusa, S., Jingu, S., et al. (2010) Relationship between Obesity and Physical Fitness and Periodontitis. Journal of Periodontology, 81, 1124-1131. http://dx.doi.org/10.1902/jop.2010.100017

[39] Chaffee, B.W. and Weston, S.J. (2010) Association between Chronic Periodontal Disease 
and Obesity: A Systematic Review and Meta-Analysis. Journal of Periodontology, 81, 17081724. http://dx.doi.org/10.1902/jop.2010.100321

[40] Saxlin, T., Ylöstalo, P., Suominen-Taipale, L., Männistö, S. and Knuuttila, M. (2011) Association between Periodontal Infection and Obesity: Results of the Health 2000 Survey. Journal of Clinical Periodontology, 38, 236-242. http://dx.doi.org/10.1111/j.1600-051X.2010.01677.x

[41] Timonen, P., Niskanen, M., Suominen-Taipale, L., Jula, A., Knuuttila, M. and Ylöstalo, P. (2010) Metabolic Syndrome, Periodontal Infection, and Dental Caries. Journal of Dental Research, 89, 1068-1073. http://dx.doi.org/10.1177/0022034510376542

[42] Morita, T., Yamazaki, Y., Mita, A., Takada, K., Seto, M., Nishinoue, N., et al. (2010) A Cohort Study on the Association between Periodontal Disease and the Development of Metabolic Syndrome. Journal of Periodontology, 81, 512-519. http://dx.doi.org/10.1902/jop.2010.090594

[43] Hatipoglu, H., Yaylak, F. and Gungor, Y. (2015) A Brief Review on the Periodontal Health in Metabolic Syndrome Patients. Diabetes \& Metabolic Syndrome: Clinical Research \& Reviews, 9, 124-126. http://dx.doi.org/10.1016/j.dsx.2015.02.007

[44] Taylor, G.W., Burt, B.A., Becker, M.P., Genco, R.J., Shlossman, M., Knowler, W.C., et al. (1996) Severe Periodontitis and Risk for Poor Glycemic Control in Patients with NonInsulin-Dependent Diabetes Mellitus. Journal of Periodontology, 67, 1085-1093.

http://dx.doi.org/10.1902/jop.1996.67.10s.1085

[45] Karjalainen, K.M., Knuuttila, M.L. and von Dickhoff, K.J. (1994) Association of the Severity of Periodontal Disease with Organ Complications in Type 1 Diabetic Patients. Journal of Periodontology, 65, 1067-1072. http://dx.doi.org/10.1902/jop.1994.65.11.1067

[46] Moore, P.A., Weyant, R.J., Mongelluzzo, M.B., Myers, D.E., Rossie, K., Guggenheimer, J., et al. (1998) Type 1 Diabetes Mellitus and Oral Health: Assessment of Tooth Loss and Edentulism. Journal of Public Health Dentistry, 58, 135-142.

http://dx.doi.org/10.1111/j.1752-7325.1998.tb02498.x

[47] Moore, P.A., Weyant, R.J., Etzel, K.R., Guggenheimer, J., Mongelluzzo, M.B., Myers, D.E., et al. (1999) Type 1 Diabetes Mellitus and Oral Health: Assessment of Periodontal Disease. Journal of Periodontology, 70, 409-417. http://dx.doi.org/10.1902/jop.1999.70.4.409

[48] Thorstensson, H., Kuylenstierna, J. and Hugoson, A. (1996) Medical Status and Complications in Relation to Periodontal Disease Experience in Insulin-Dependent Diabetics. Journal of Clinical Periodontology, 23, 194-202. http://dx.doi.org/10.1111/j.1600-051X.1996.tb02076.x

[49] Shultis, W.A., Weil, E.J., Looker, H.C., Curtis, J.M., Shlossman, M., Genco, R.J., et al. (2007) Effect of Periodontitis on Overt Nephropathy and End-Stage Renal Disease in Type 2 Diabetes. Diabetes Care, 30, 306-311. http://dx.doi.org/10.2337/dc06-1184

[50] Ide, R., Hoshuyama, T., Wilson, D., Takahashi, K. and Higashi, T. (2011) Periodontal Disease and Incident Diabetes: A Seven-Year Study. Journal of Dental Research, 90, 41-46. http://dx.doi.org/10.1177/0022034510381902

[51] Demmer, R.T., Desvarieux, M., Holtfreter, B., Jacobs Jr., D.R., Wallaschofski, H., Nauck, M., et al. (2010) Periodontal Status and A1C Change: Longitudinal Results from the Study of Health in Pomerania (SHIP). Diabetes Care, 33, 1037-1043. http://dx.doi.org/10.2337/dc09-1778

[52] Demmer, R.T., Jacobs Jr., D.R., Singh, R., Zuk, A., Rosenbaum, M., Papapanou, P.N. and Desvarieux, M. (2015) Periodontal Bacteria and Prediabetes Prevalence in ORIGINS: The Oral Infections, Glucose Intolerance, and Insulin Resistance Study. Journal of Dental 
Research, 94, S201-S211. http://dx.doi.org/10.1177/0022034515590369

[53] Preshaw, P.M. and Taylor, J.J. (2011) How Has Research into Cytokine Interactions and Their Role in Driving Immune Responses Impacted Our Understanding of Periodontitis? Journal of Clinical Periodontology, 38, 60-84. http://dx.doi.org/10.1111/j.1600-051X.2010.01671.x

[54] Dandona, P., Aljada, A. and Bandyopadhyay, A. (2004) Inflammation: The Link between Insulin Resistance, Obesity and Diabetes. Trends in Immunology, 25, 4-7. http://dx.doi.org/10.1016/j.it.2003.10.013

[55] Brownlee, M. (2005) The Pathobiology of Diabetic Complications: A Unifying Mechanism. Diabetes, 54, 1615-1625. http://dx.doi.org/10.2337/diabetes.54.6.1615

[56] Preshaw, P.M., Alba, A.L., Herrera, D., Jepsen, S., Konstantinidis, A., Makrilakis, K., et al. (2012) Periodontitis and Diabetes: A Two-Way Relationship. Diabetologia, 55, 21-31. http://dx.doi.org/10.1007/s00125-011-2342-y

[57] Taylor, J.J., Preshaw, P.M. and Lalla, E. (2013) A Review of the Evidence for Pathogenic Mechanisms That May Link Periodontitis and Diabetes. Journal of Periodontology, 84, S113-S134. http://dx.doi.org/10.1111/jcpe.12059

[58] Shetty, N., Thomas, B. and Ramesh, A. (2008) Comparison of Neutrophil Functions in Diabetic and Healthy Subjects with Chronic Generalized Periodontitis. Journal of Indian Society of Periodontology, 12, 41-44. http://dx.doi.org/10.4103/0972-124X.44089

[59] Ajith, T.A. and Vinodkumar, P. (2016) Advanced Glycation End Products: Association with the Pathogenesis of Diseases and the Current Therapeutic Advances. Current Clinical Pharmacology, 11, 118-127. http://dx.doi.org/10.2174/1574884711666160511150028

[60] Schmidt, A.M., Weidman, E., Lalla, E., Yan, S.D., Hori, O., Cao, R., et al. (1996) Advanced Glycation End Products (AGEs) Induce Oxidant Stress in the Gingiva: A Potential Mechanism Underlying Accelerated Periodontal Disease Associated with Diabetes. Journal of Periodontal Research, 31, 508-515. http://dx.doi.org/10.1111/j.1600-0765.1996.tb01417.x

[61] Grover, H.S. and Luthra, S. (2013) Molecular Mechanisms Involved in the Bidirectional Relationship between Diabetes Mellitus and Periodontal Disease. Journal of Indian Society of Periodontology, 17, 292-301. http://dx.doi.org/10.4103/0972-124X.115642

[62] Chapple, I.L., Genco, R. and Working Group 2 of the Joint EFP/AAP Workshop (2013) Diabetes and Periodontal Diseases: Consensus Report of the Joint EFP/AAP Workshop on Periodontitis and Systemic Diseases. Journal of Periodontology, 40, S106-S112. http://dx.doi.org/10.1111/jcpe.12077

[63] Bullon, P., Morillo, J.M,, Ramirez-Tortosa, M.C., Quiles, J.L., Newman, H.N. and Battino, M. (2009) Metabolic Syndrome and Periodontitis: Is Oxidative Stress a Common Link? Journal of Dental Research, 88, 503-518. http://dx.doi.org/10.1177/0022034509337479

[64] D’Aiuto, F., Nibali, L., Parkar, M., Patel, K., Suvan, J. and Donos, N. (2010) Oxidative Stress, Systemic Inflammation, and Severe Periodontitis. Journal of Dental Research, 89, 1241-1246. http://dx.doi.org/10.1177/0022034510375830

[65] Nibali, L. and Donos, N. (2013) Periodontitis and Redox Status: A Review. Current Pharmaceutical Design, 19, 2687-2697. http://dx.doi.org/10.2174/1381612811319150003

[66] Marchetti, E., Monaco, A., Procaccini, L., Mummolo, S., Gatto, R., Tetè, S., et al. (2012) Periodontal Disease: The Influence of Metabolic Syndrome. Nutrition \& Metabolism, 9, 88. http://dx.doi.org/10.1186/1743-7075-9-88

[67] Thorstensson, H., Dahlen, G. and Hugoson, A. (1995) Some Suspected Periodontopathogens and Serum Antibody Response in Adult Long-Duration Insulin-Dependent Diabetics. Journal of Clinical Periodontology, 22, 449-458. 
http://dx.doi.org/10.1111/j.1600-051X.1995.tb00176.x

[68] Takahashi, K., Nishimura, F., Kurihara, M., Iwamoto, Y., Takashiba, S., Miyata, T., et al. (2001) Subgingival Microflora and Antibody Responses Against Periodontal Bacteria of Young Japanese Patients with Type 1 Diabetes Mellitus. Journal of the International Academy of Periodontology, 3, 104-111.

[69] Kiran, M., Arpak, N., Unsal, E. and Erdoğan, M.F. (2005) The Effect of Improved Periodontal Health on Metabolic Control in Type 2 Diabetes Mellitus. Journal of Clinical Periodontology, 32, 266-272. http://dx.doi.org/10.1111/j.1600-051X.2005.00658.x

[70] Navarro-Sanchez, A.B., Faria-Almeida, R. and Bascones-Martinez, A. (2007) Effect of Non-Surgical Periodontal Therapy on Clinical and Immunological Response and Glycaemic Control in Type 2 Diabetic Patients with Moderate Periodontitis. Journal of Clinical Periodontology, 34, 835-843. http://dx.doi.org/10.1111/j.1600-051X.2007.01127.x

[71] Singh, S., Kumar, V., Kumar, S. and Subbappa, A. (2008) The Effect of Periodontal Therapy on the Improvement of Glycemic Control in Patients with Type 2 Diabetes Mellitus: A Randomized Controlled Clinical Trial. International Journal of Diabetes in Developing Countries, 28, 38-44.

[72] Al-Mubarak, S., Ciancio, S., Aljada, A., Mohanty, P., Ross, C. and Dandona, P. (2002) Comparative Evaluation of Adjunctive Oral Irrigation in Diabetics. Journal of Clinical Periodontology, 29, 295-300. http://dx.doi.org/10.1034/j.1600-051X.2002.290404.x

[73] Koromantzos, P.A., Makrilakis, K., Dereka, X., Katsilambros, N., Vrotsos, I.A. and Madianos, P.N. (2011) A Randomized, Controlled Trial on the Effect of Non-Surgical Periodontal Therapy in Patients with Type 2 Diabetes. Part I: Effect on Periodontal Status and Glycaemic Control. Journal of Clinical Periodontology, 38, 142-147. http://dx.doi.org/10.1111/j.1600-051X.2010.01652.x

[74] Santos, V.R., Lima, J.A., de Mendonca, A.C., Braz Maximo, M.B., Faveri, M. and Duarte, P.M. (2009) Effectiveness of Full-Mouth and Partial-Mouth Scaling and Root Planing in Treating Chronic Periodontitis in Subjects with Type 2 Diabetes. Journal of Periodontology, 80, 1237-1245. http://dx.doi.org/10.1902/jop.2009.090030

[75] Martorelli de Lima, A.F., Cury, C.C., Palioto, D.B., Duro, A.M., da Silva, R.C. and Wolff, L.F. (2004) Therapy with Adjunctive Doxycycline Local Delivery in Patients with Type 1 Diabetes Mellitus and Periodontitis. Journal of Clinical Periodontology, 31, 648-653. http://dx.doi.org/10.1111/j.0303-6979.2004.00576.x

[76] Llambes, F., Silvestre, F.J., Hernandez-Mijares, A., Guiha, R. and Caffesse, R. (2008) The Effect of Periodontal Treatment on Metabolic Control of Type 1 Diabetes Mellitus. Clinical Oral Investigations, 12, 337-343. http://dx.doi.org/10.1007/s00784-008-0201-0

[77] Janket, S.J., Wightman, A., Baird, A.E., Van Dyke, T.E. and Jones, J.A. (2005) Does Periodontal Treatment Improve Glycemic Control in Diabetic Patients? A Meta-Analysis of Intervention Studies. Journal of Dental Research, 84, 1154-1159.

http://dx.doi.org/10.1177/154405910508401212

[78] Teeuw, W.J., Gerdes, V.E. and Loos, B.G. (2010) Effect of Periodontal Treatment on Glycemic Control of Diabetic Patients: A Systematic Review and Meta-Analysis. Diabetes Care, 33, 421-427. http://dx.doi.org/10.2337/dc09-1378

[79] Spangler, L., Reid, R.J., Inge, R., Newton, K.M., Hujoel, P., Chaudhari, M., et al. (2010) Cross-Sectional Study of Periodontal Care and Glycosylated Hemoglobin in an Insured Population. Diabetes Care, 33, 1753-1758. http://dx.doi.org/10.2337/dc09-1412

[80] Gurav, A.N. (2012) Periodontal Therapy-An Adjuvant for Glycemic Control. Diabetes \& Metabolic Syndrome: Clinical Research \& Reviews, 6, 218-223. 
http://dx.doi.org/10.1016/j.dsx.2012.09.007

[81] Simpson, T.C., Weldon, J.C., Worthington, H.V., Needleman, I., Wild, S.H., Moles, D.R., et al. (2015) Treatment of Periodontal Disease for Glycaemic Control in People with Diabetes Mellitus. Cochrane Database of Systematic Reviews, 6, CD004714. http://dx.doi.org/10.1002/14651858.cd004714.pub3

[82] Stratton, I.M., Adler, A.I., Neil, H.A., Matthews, D.R., Manley, S.E., Cull, C.A., et al. (2000) Association of Glycaemia with Macrovascular and Microvascular Complications of Type 2 Diabetes (UKPDS 35): Prospective Observational Study. British Medical Journal, 321, 405412. http://dx.doi.org/10.1136/bmj.321.7258.405

[83] Matthews, D.C. (2002) The Relationship between Diabetes and Periodontal Disease. Journal of the Canadian Dental Association, 68, 161-164.

[84] Watanabe, K. (2011) Periodontitis in Diabetics: Is Collaboration between Physicians and Dentists Needed? Disease-a-Month, 57, 206-213. http://dx.doi.org/10.1016/j.disamonth.2011.03.007

[85] Lalla, E., Kunzel, C., Burkett, S., Cheng, B. and Lamster, I.B. (2011) Identification of Unrecognized Diabetes and Pre-Diabetes in a Dental Setting. Journal of Dental Research, 90, 855-860. http://dx.doi.org/10.1177/0022034511407069

[86] Aguilar-Salvatierra, A., Calvo-Guirado, J.L., González-Jaranay, M., Moreu, G., DelgadoRuiz, R.A. and Gómez-Moreno, G. (2016) Peri-Implant Evaluation of Immediately Loaded Implants Placed in Esthetic Zone in Patients with Diabetes Mellitus Type 2: A Two-Year Study. Clinical Oral Implants Research, 27, 156-161. http://dx.doi.org/10.1111/clr.12552

[87] Gómez-Moreno, G., Aguilar-Salvatierra, A., Rubio Roldán, J., Guardia, J., Gargallo, J. and Calvo-Guirado, J.L. (2015) Peri-Implant Evaluation in Type 2 Diabetes Mellitus Patients: A 3-Year Study. Clinical Oral Implants Research, 26, 1031-1035.

http://dx.doi.org/10.1111/clr.12391 


\section{Abbreviation Note List}

PD: Periodontal Diseases

DM: Diabetes Mellitus

IDF: International Diabetes Federation

CRP: C-reactive protein

NHANES: National Health and Nutrition Examination Study

HbA1c: Glycosylated hemoglobin

ESRD: End-Stage Renal Disease

IHD: Ischemic Heart Disease

CVD: Cardiovascular Diseases

IL- $1 \beta$, IL-6: Interleukins $1 \beta$ and 6

PGE2: Prostaglandin E2

TNFa: Tumor Necrosis Factor alpha

RANKL: Receptor activator of nuclear factor kappa-B ligand

AGE: Advanced Glycosylation End-products

RAGE: Receptor of advanced glycosylation end-products

MMP: Extracellular Matrix Metalloproteinases

PMN: Polymorphonuclear leukocytes

ROS: Reactive Oxygen Species

Submit or recommend next manuscript to SCIRP and we will provide best service for you:

Accepting pre-submission inquiries through Email, Facebook, LinkedIn, Twitter, etc.

A wide selection of journals (inclusive of 9 subjects, more than 200 journals)

Providing 24-hour high-quality service

User-friendly online submission system

Fair and swift peer-review system

Efficient typesetting and proofreading procedure

Display of the result of downloads and visits, as well as the number of cited articles

Maximum dissemination of your research work

Submit your manuscript at: http://papersubmission.scirp.org/ 